\title{
A new born in a refrigerator
}

Rajapaksha WRAS, Wijerathna NASP

W.R.A.S.Rajapaksha ${ }^{1}$, N.A.S.P.Wijerathna ${ }^{1}$

Department of Forensic Medicine, Faculty of Medicine, Ragama ${ }^{1}$

*Corresponding author: Tel: 0094-71-4492887. E-mail address:

samindarajapaksha@yahoo.com

MLSSL. Vol 1. No 2. Aug. pp $56-59$

\section{Abstract}

Introduction: Killing of a baby by its own mother is known from biblical times to the modern era. Challenges faced by the forensic pathologist in an investigation of a case of infanticide include proof of live birth, age of the baby, link between the mother and the baby, and the commission or omission of an act causing the death of the baby by its own mother. The case under discussion illustrates how these challenges were met.

Case report: The fresh body of an infant was found in the deep freezer compartment of a refrigerator in a house. Autopsy examination revealed a mature baby boy with multiple cut injuries in the neck. Lungs were fully expanded and there was aspirated blood in the distal air passage indicating signs of live birth. Medico-legal examination of the mother revealed breast engorgement and recent vaginal delivery including the presence of placenta. Psychiatric referral revealed moderate depression of the mother.

Conclusion: The case was an unusual case of infanticide where the mother killed her baby using a drastic method and concealed the body. Forensic investigations assisted in establishing live birth and maternal depression possibly associated with puerperal psychosis.

Key words: Killing of a baby, mother, cut injuries, refrigerator

\section{Introduction}

Killing of an infant by his/her own mother is known from biblical times to modern days. Challenges faced by forensic pathologists in an investigation of a case of 


\section{Case report}

The fresh body of an infant was found in the deep freezer compartment of a domestic refrigerator. The police reported that a 38 year old married mother of 2 children had cut her own $3^{\text {rd }}$ baby's neck with a kitchen knife soon after a home delivery. Autopsy examination revealed a freshly born, well grown, mature baby boy with the piece of umbilical cord attached. There was no evidence of maceration, such as collapsed skull bones or gross congenital abnormalities. The weight of the baby was $2900 \mathrm{~g}$ and crown heel length was $53 \mathrm{~cm}$. There was well grown scalp hair, nails and breast buds.

There were 04 almost transversely placed cut injuries on the front of the neck across the midline; one of which had severed the trachea and the left carotid artery with evidence of bleeding in the wound edges. (Fig. 3)Both lungs were fully expanded and showed signs of full respiration. Distal air passages were filled with frank blood. Microscopy revealed fully expanded alveoli in all major lobes of both lungs and the presence of intra-alveolar haemorrhages.(micrograph 1) All major organs were pale and flabby. The examination of the locus revealed multiple blood stains and pooling of blood on the floor of the kitchen of the recently built house. (Fig 1) There were blood stains on the freezer compartment of the refrigerator and its door. (Fig 2) Blood soaked clothes were found hidden inside a dustbin.

Examination of the alleged mother revealed the physiological changes of pregnancy and recent vaginal delivery. Samples were taken for DNA studies.
The alleged mother was later diagnosed to have moderate depression and treated with electroconvulsive therapy. Past medical history was free from major psychiatric illness or puerperal psychosis in relation to previous pregnancies.

\section{Discussion}

Infanticide is the death of a baby under one year of age, due to acts of commission or omission by its mother while the balance of her mind is disturbed by the effects of delivery and or lactation [1-3] while filicide is the deliberate act of a parent killing his or her son or daughter [4]. This crime has occurred since biblical times to modern era. Infanticide is more common with illegitimate and unwanted pregnancies. Usually perpetrators of infanticide are young, unmarried and illiterate and suffer from psychiatric disorders and or psychosocial stressors but there is no history of criminal behavior, and no suicidal attempts following incidents [4].

The methods of killing are usually suffocation, strangulation, blows on the head, or dashing the child against the wall, submersion in water by putting in a toilet or in a bucket of water or omission by neglecting to do what is absolutely necessary for the newly-born child.[4] Cutting of the neck is relatively rare. But cutting of the neck and concealment in a refrigerator is even more rare [5].

In this case, this mature well grown child had fully expanded lungs and blood in the distal air passages. Presence of blood in the trachea is possible with the cut injuries to the trachea. However presence of blood in the distal air passages including alveoli in this recumbent baby indicates possible live aspiration. Presence of haemorrhagic wound edges further supports live birth. 
Therefore the cause of death was concluded as complications of multiple cut injuries to the neck in a new born.

The mother showed evidence of recent pregnancy and delivery. The relationship between the mother and the baby in this case could be achieved by the circumstantial evidence alone. Maternal depression was confirmed at psychiatric examination. Puerperal psychosis is now a well-recognized event, affecting perhaps one in every 500 births in the UK [6] Depression is a major feature associated with it. [7] Perusal of literature shows that mothers who kill their children often have experienced psychosis, suicidality, depression, and considerable life stress [8].

\section{Conclusion}

The case was an unusual case of infanticide where the mother had killed her baby using a much drastic method and concealed the body. The forensic investigators could establish live birth and maternal depression possibly associated with puerperal psychosis.

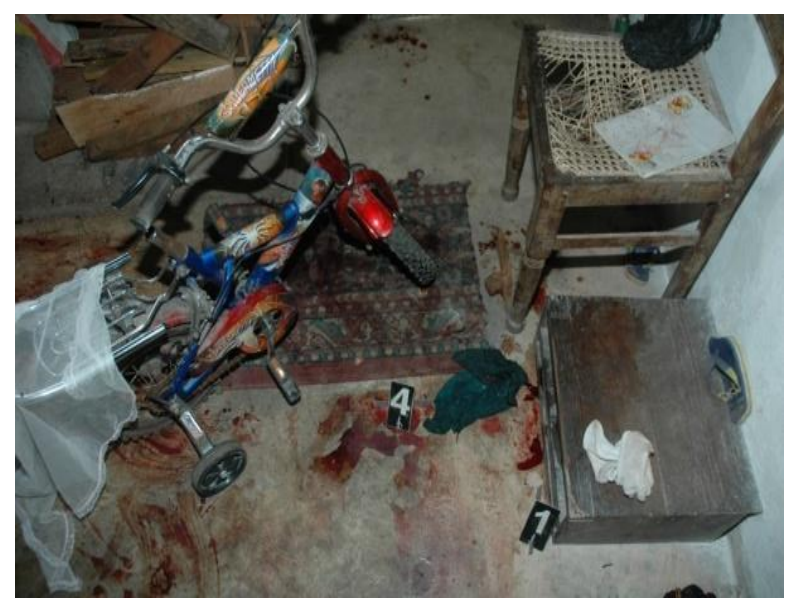

Fig 1- the scene of crime

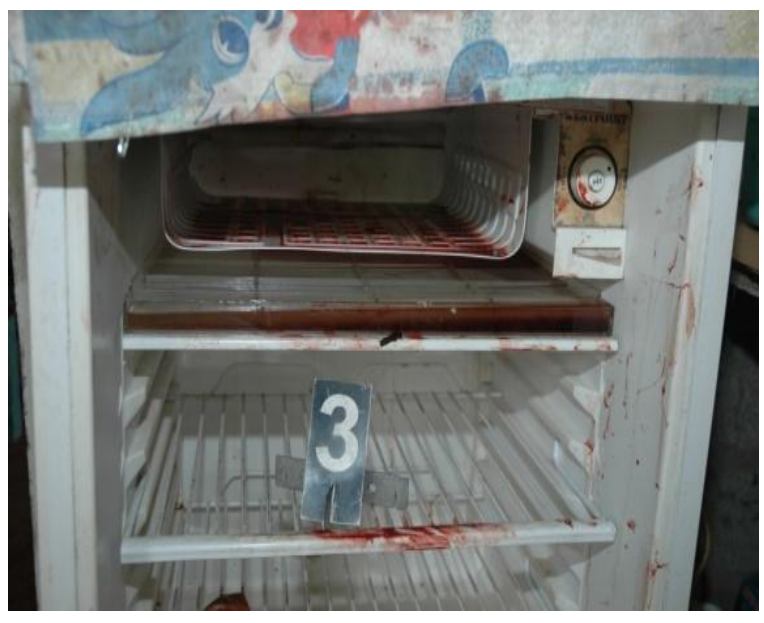

Fig 2 - pooling of blood in the refrigerator

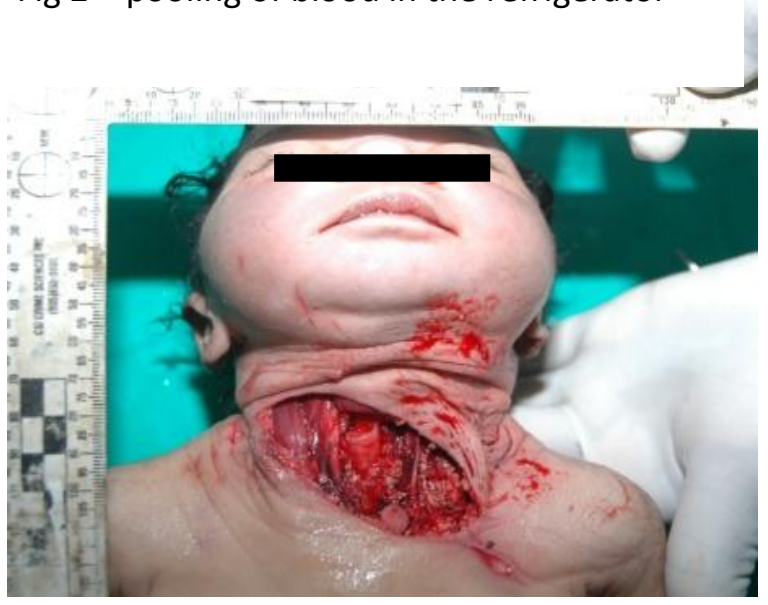

Fig 3- baby boy with cut injuries

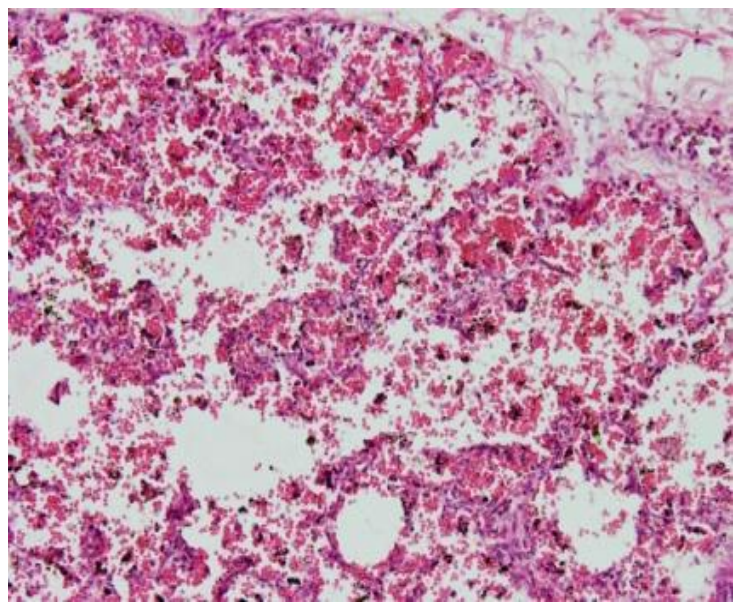

Micrograph 1- histology of lung showing well expanded alveoli filled with blood 


\section{References}

1. Praveen S, Case Report Female Infanticide J Indian Acad Forensic Med. October- December 2011, Vol. 33, No. 4 ISSN 0971-0973 366

2. Hässler F, Zamorski H, Weirich S. The problem of differentiating between sudden infant death syndrome, fatal Munchausen's syndrome by proxy, and infanticide. $\quad Z$ Kinder Jugendpsychiatr Psychother. 2007 Jul;35(4):237-44; quiz 245-6.

3. TH. Meera Devi. Extreme Cases of Child Abuse by Parents, A Report on a Series of 4 Different Cases;Vol. 8, No. 1 (200801 - 2008-06

4. Elsharkawy A.S , Ragaa M. AbdelMaaboud R M , Mohamed A.A and Mohamed H. Abd El Hakim; The Medicolegal Aspects of Infanticide Cases; Forensic Medicine and Clinical Toxicology Department , Faculty of Medicine, Assiut University, Medicolegal Department, Ministry of Justice, Egypt
5 M. Marciki et al.: Infanticide in Eastern Croatia, Coll. Antropol. 30 (2006) 2: 437442

6 Infant-killing and the Victorian mother, BBC News, Last Updated: Sunday, 15 June, 2003, 23:39 GMT 00:39 UK

7 Dorothy Sit, Anthony J. Rothschild, and Katherine L. Wisner, Depression is one of the major features of postmortem psychosis. A Review of Postpartum Psychosis. J Womens Health (Larchmt). 2006 May; 15(4): 352-368.

8 Friedman SH, Horwitz SM, Resnick PJ. Child murder by mothers: a critical analysis of the current state of knowledge and a research agenda. American J Psychiatry. 2005; 162:1578-1587.

\section{Contribution of authors}

Performing the autopsy- WRASR

Opinion- WRASR, NASPW

Writing the manuscript -WRASR

Revising the manuscript- WRASR, NASPW 